\title{
A CIDADE EM CHOQUE
}

\author{
Leandro Medrano
}

Em 1981, o crítico Kenneth Frampton publica a primeira edição do livro História Crítica da Arquitetura Moderna, um dos relatos mais importantes e polêmicos sobre a arquitetura produzida no século 20 , ou mais precisamente, da arquitetura e do urbanismo que surgem como decorrência dos avanços da técnica e das transformações sociais que ocorrem na Europa a partir do século 19. Em seu epílogo, Frampton ressalta os logros das urbanizações adensadas e de verticalização moderada - nos moldes das cidades europeias do século 19 -, como alternativa aos vazios ou a monotonia das urbanizações "modernas" - de torres ou blocos espalhados por áreas verdes e conexões viárias rodoviaristas. Em relação à arquitetura, suas posições convergem com a crítica que emerge nos anos 1960, sobretudo a partir dos escritos de Manfredo Tafuri. Ou seja, Frampton não vislumbra uma trajetória otimista à disciplina em seu enfrentamento com a sociedade de consumo, o neoliberalismo e o urbanismo de mercado. Para o autor, o fim das utopias, ou dos ideais que fundamentaram parte da Arquitetura Moderna, em seu momento seminal, não logrou alternativas consistentes aos argumentos teóricos capazes de manter o vigor criativo e social das ideias promotoras da Nova Arquitetura. Desse modo, para não seguir rumo à obsolescência, seria necessário um retorno ao lugar, às dimensões materiais e culturais das circunstâncias, nos moldes do famoso termo cunhado pelo autor: "o regionalismo crítico".

Nas décadas seguintes ao lançamento do História Crítica da Arquitetura Moderna, marcadas pelo avanço do neoliberalismo e da globalização, o que se pode ver foi o acirramento em velocidade única dos mecanismos visionados pelos críticos aos padrões de produção e consumo da pós-modernidade. A relação entre técnica e arquitetura passa a priorizar a variedade "criativa" exigida pelos mecanismos de marketing e pela sociedade de massas. Ademais, procurou-se legitimar essa nova integração entre a indústria (cultural) e a sociedade pela "cientifização" de processos de projeto - com usos de novas ferramentas computacionais, abstratos modelos analíticos e vigorosas artimanhas retóricas e teóricas. Não parecia haver limites para o potencial de inovação formal das arquiteturas resultantes dos lucros proporcionados por um sistema financeiro desregulamentado e globalizado, que agenciou governantes de todo o mundo a promoverem grandes obras a custos exorbitantes, financiadas por capitais fictícios, voláteis e com imprecisas expectativas de retorno.

O início do século 21 tem demonstrado que as questões apontadas nos anos 1960 permanecem sem solução, e que o conformismo com a arquitetura de mercado ou com a cidade-mercadoria, agravou consideravelmente as perspectivas da disciplina. Pois os avanços da técnica não resultaram em alternativas aplicadas em grande escala, e o experimentalismo estético, levado ao seu limite, acomodou bizarras performances espaciais e programáticas. A arquitetura como produto, sem perspectiva estética ou ética, se mostrou um objeto caro, pouco lucrativo e irrelevante - pois não é descartável e volátil como os outros bens consumidos pela sociedade de massas, e como ativo fixo é dependente dos arranjos financeiros vigentes. Ademais, após a crise de 2008, a extravagância exibida na década de 1990 e no início do século 21, deixou de simbolizar a hegemonia do capitalismo e os prazeres de seus vencedores e passou a representar as ilícitas formas do capital financeiro globalizado, as altas taxas de corrupção nas esferas governamentais e a irresponsabilidade dos Estados submetidos às regras do mercado. Revela-se um esquema insustentável de produção, consumo e financeirização, se considerarmos os termos de 
autores como René Passet, Tony Judt, David Harvey, Fredric Jameson e, mais recentemente, Thomas Piketty. Neste contexto, grande parte da arquitetura e das intervenções urbanas do período hoje tornaram-se símbolo de um sistema econômico e social em descrédito - monumentos de uma realidade distópica.

Se o crash de 2008 demonstrou os limites de um modelo econômico em emergência desde a segunda metade do século 20, os entraves políticos acentuados em 2016, no Brasil e no mundo, indicam poucas perspectivas para um futuro próximo. Pois acirraram-se os conflitos decorrentes das forças reacionárias que corroboram com as desigualdades, os conflitos étnicos, a xenofobia, o sexismo, a homofobia, a democracia, a livre circulação de ideias - um retrocesso à chamada "era do humanismo". Se os efeitos desse póshumanismo parecem ser devastadores para todos os campos da vida social, o "novo mundo" em formação pode sinalizar o fim da arquitetura, do urbanismo e das cidades.

Este número da Revista Pós contém um conjunto de artigos acadêmicos que tratam, direta ou indiretamente, dessa inflexão singular nos rumos da Modernidade dada a partir do Segundo Pós-Guerra, ou, mais precisamente, dos anos 1960.

No artigo Los Angeles, a metrópole radical de Reyner Banham, Regina Meyer faz um instigante e atual resgate das ideias de Banham expostas no livro Los Angeles - a arquitetura de quatro ecologias, publicado originalmente em 1971, com edição em português de 2013. A autora ressalta a originalidade do método e da postura crítica de Banham, que ao deparar-se com uma forma nova e excêntrica de urbanização, sinaliza suas oportunidades e desafios - em direção oposta tanto aos ditames Modernos previstos nos Congressos Internacionais de Arquitetura Moderna (CIAMs), quanto às críticas ao sprawl que começavam a ser formuladas à época. Reyner Banham ao propor a ideia da metrópole como um processo, como uma construção permanente, pode auxiliar o entendimento de outras metrópoles radicais, como São Paulo.

O filme $A$ Idade da Terra, de Glauber Rocha, é o objeto de estudo de Ilana Schlaich Tschiptschin, em seu ensaio Brasília em a Idade da Terra: Apontamentos para uma Análise

Figural. A autora busca elaborar uma narrativa por meio da leitura e interpretação de três sequências do filme. 0 resultado revela que as contradições dessa versão dos trópicos de cidade Moderna instigam, desde sua criação, as mais diversas interpretações. Contudo, o destaque é dado à narrativa elaborada pelo cineasta Glauber Rocha, que evidencia a exploração do "Terceiro Mundo" pelo capital estrangeiro. Nota-se, passadas quase três décadas, que os problemas estruturais do País e de Brasília permanecem os mesmos.

O experimentalismo do grupo de arquitetos Iondrinos Archigram nos anos 1960, sobretudo, o projeto Instant City, é o tema do artigo Invenções de arquitetura - uma análise de Instant City como proposta experimental arquitetônica, de Adriane Silvério. O meio urbano em transformação, articulado por entre aparatos tecnológicos e novas sensibilidades estéticas e sociais, conformaria uma ideia de cidade fundamentada em sua efemeridade - em arquiteturas fragmentadas, flexíveis, mutáveis. Os vestígios das utopias tecnocientíficas assentados por uma sofisticada narrativa iconográfica e elaborados desenhos de arquitetura - fazem do Archigram uma referência ainda atual a projetos experimentais, que buscam diálogo entre as possibilidades infinitas das tecnologias ligadas à construção civil e aos processos de interação social.

O artigo Cidade Ausente: Interdisciplinaridade de um Sentimento Urbano entre a Música e a Migração Brasileira, de Gisela Cunha Viana Leonelli e Rafael Baldam busca compreender 
o processo de urbanização brasileiro dos anos 1960-1970 por meio da interpretação de algumas canções populares. Partindo da premissa de que os estudos sobre a cidade devem considerar os múltiplos processos que envolvem sua formação, os autores entenderam que a música poderia revelar um certo "sentimento urbano" do período em estudo. Tempos de intensificado processo de urbanização e de crescimento dos conflitos urbanos gerados pela migração.

\section{Em Imigrantes Coreanos na Formação do Polo Atacadista de Moda Feminina de Pronta-} Entrega no Bairro do Bom Retiro, São Paulo, Jung Yun Chi retrata a evolução histórica do bairro do Bom Retiro considerando as transformações advindas dos imigrantes coreanos dedicados à produção e ao comércio têxteis. Trata-se de um profícuo relato das recentes transformações espaciais da região central da cidade de São Paulo - que nos revela uma metrópole em movimento, que ajusta-se continuamente as suas dinâmicas produtivas internas e às demandas externas de um mundo globalizado.

Fábio Ferreira de Lima, no artigo Realidades Criativas do Campo Estético: Hibridismo entre Arte e Arquitetura Digital, faz uma ampla revisão de autores que, nas últimas décadas, exploraram a relação entre os meios digitais de produção e o processo de projeto em arquitetura. Destaca as possibilidades ofertadas pelas ferramentas computacionais, que poderiam propor ou criar novos padrões de expressão pela combinação da ciência, da tecnologia e da arte. Desses "terrenos hibridizados" seriam formuladas inusitadas arquiteturas, talvez mais próximas a um cotidiano, para o bem e para o mal, cada vez mais imerso nos signos e formas decorrentes dos meios digitais.

Os efeitos da morfologia urbana na temperatura ambiente e nos gastos energéticos é o tema do artigo Surface Urban Heatls landand buildings energy: visualization of urban climatic flows, de Jorge Rodríguez-Álvarez. Por meio da análise de dados e imagens coletados por satélites e com dados processados em GIS, autor analisa os efeitos das Surface Urban Heatlsland (SUHI) em diversas cidades Europeias, com ênfase para a demanda energética dos edifícios habitacionais das cidades de Londres e Barcelona. Além dos resultados práticos apontados no artigo, o trabalho ressalta a diversidade de instrumentos disponíveis para as análises dos tecidos urbanos - um terreno ainda pouco explorado pelo urbanismo, mas promissor se consideramos o impacto econômico, social e ambiental das decisões urbanas em um mundo onde grande parte das populações vivem em grandes metrópoles em acelerado crescimento.

A correlação entre o conforto térmico, o desempenho energético e o processo de projeto é tema do artigo Desempenho Termo-Energético de Edifícios Residenciais em Clima

Temperado, de Márcia Cristina Pereira Tavares, Hélder José Perdigão Gonçalves e Jorge Novais Telles de Faria Corrêa Bastos. Para tanto, são utilizados medições em loco e simulações térmicas por meio do programa Energy Plus. São analisados vários edifícios de habitação coletiva situados em Lisboa e os resultados alcançados revelam diretrizes importantes para as decisões de projetos localizados em locais de clima mediterrâneo.

Boa leitura!

Leandro Medrano

Editor-Chefe Revista Pós

medrano@usp.br 